DOI: 10.14526/2070-4798-2019-14-4-32-39

\title{
Competitive activity effectiveness estimation among basketball players of student teams taking into account their type of temperament
}

\author{
PushkarevA.V.* \\ Institute of Physical Culture and Sport \\ Udmurtiya State University \\ Izhevsk, Russia \\ ORCID: oooo-0oo2-6192-4624, Alexeipushkarev@mail.ru*
}

\begin{abstract}
The article considers the effectiveness estimation of players' competitive activity at national student basketball teams. Basketball as a team game takes central place in the life of students, who entered higher educational establishments. At contemporary stage of its development basketball is characterized by good technical and physical training, but insufficient psychological and volitional readiness of players. In this connection the problem of psychological training improvement in national student teams is very urgent in scientific research works. It was revealed that the factors of psychological training for competitions can be players' psychological readiness for competitions formation, correct psycho-regulation means use, taking into account personality's features of each player. Materials. For further competitive readiness improvement in student basketball teams it is necessary to estimate competitive activity of each player, taking into account their types of temperament. Such an approach helps to improve the effectiveness of their competitive activity. The average amount and the effectiveness of technical-tactical actions in basketball players were revealed, taking into account their types of temperament. We also revealed the effectiveness and activity of players during the game, taking into account their type of temperament. Methods. Information sources analysis; basketball players' types of temperament revelation using hardware-controlled testing «D\&K-TEST» (season 2017-2018); we revealed the effectiveness indices among the players on the basis of video, using CANON MV700 camera (Japan). Results. The work presents the indices of play effectiveness, taking into account the type of basketball players' temperament. The amount and effectiveness of technicaltactical actions fulfillment (correct) during the game in basketball players with different types of temperament (season of games 2017-2018). Play effectiveness indices were analyzed taking into account the type of basketball players' temperament. We revealed and analyzed the indices of expert estimation and not successful technical-tactical actions (TTA) and play situations of basketball players. Conclusion.Thus, the ability of players to fulfill effective TTA depends on their personal psychic qualities demonstration; successful and not successful TTA analysis and taking part in playing situations, which lead to scoring chances, helps to correct players' psychic readiness state; taking into account the types of players' temperament helps to realize effectively psycho-regulating means of psychological training.
\end{abstract}

Keywords: students, basketball players, competitive activity, type of temperament, effectiveness coefficient, technical-tactical actions.

For citation: Pushkarev A.V.* Competitive activity effectiveness estimation in basketball players of student teams taking into account their type of temperament. Russian Journal of Physical Education and Sport. 2019; 14(4): 27-33. DOI: 10.14526/2070-4798-2019-14-4-32-39.

\section{INTRODUCTION}

Nowadays training national teams should accumulate up-to-date achievements in all parameters of training in basketball. As other kinds of sport basketball is a situation kind of sport, where players' actions happen in terms of contact between themselves and opponents. In this connection the main factor of a successful game and playing situations can be quickness of reaction, thinking and correct decisions making in playing situations.

The success of playing situations and connections depends, first of all, on the decision, which can take the member of the team. All actions are directed toward playing domination achievement over the team of opponents in all playing situations. In this connection a typical feature of playing situations in basketball is that during the whole game it is impossible to predict 
playing situations and opponents'actions. Tension of competitive play and a diverse character of playing situations, which are formed during the playing periods, create tension of players' psychic state.

Scientific-methodical and special literature analysis showed that the main factors, which demand players' psychological training development, are the following:

-technical-tactical actions taking into account depending on players' type of temperament;

- different playing situations realization depending on the typology of nervous system characteristics;

- a wide arsenal of necessary technical-tactical actions use, fulfilled in a short time periods;

-quick situational problems solution using different actions of a player;

- constant control over own actions and playing situation;

- the actions of each player estimation; obstacles;

- psychic resistance to difficulties and

- psycho-regulating means and methods realization during preparatory and competitive periods.

Scientific-methodical and special literature analysis showed that many research works consider different sides of training.

For example, V.A. Alatortsev (2009) in psychological research works studies readiness of athletes for competitions, showing the effectiveness of this approach [1].

G.D. Babushkin (1996) analyzes the use of hardware-controlled in fluences during athletes' self-control development as the base of psychological training [2].

S.M. Gordon(2004) considers the necessity to estimate psychological readiness of athletes as the base for successful competitive activity[3].

I.G. Gibadullin and others (2016) consider the necessity to study and control all indices of young athletes' readiness as the base of effective training [4].

I.A. Grigoryants (2001) studies the problems of readiness and pre-competitive training organization among gymnasts.
D.R. Zakirov (2012) studied psychic readiness state of wrestlers, taking into account individualpeculiar features of the personality $[5,6]$.

E.P. Ilin (2009), A.Ts. Puni (2008),studying the psychology of will power, mentioned the importance of volitional training in athletes $[7,12,14]$.

G.A. Kamalieva (2010) offered the system of obstacles and difficulties overcoming in training volleyball players [9].

The group of authors considers functional training as the condition for all sides of readiness demonstration. Aerobic thresholdand potentialities of cardiovascular system estimation among crosscountry racers (boys) on the basis of gradually increasing bicycle ergometric load demands taking into account psychological component [10,11,13].

The effectiveness and activity of players study depending on their types of temperament were not studied.

The aim of this research work was competitive activity studying among the players of student basketball teams, taking into account their types of temperament.

In order to achieve the aim of the research we gradually solved the following objectives:

1. On the basis of scientific-methodical literature analysis we defined the degree of the problem consideration (the problem of taking into account the type of temperament in competitive training of student basketball national team).

2.To reveal the average number and effectiveness of technical-tactical actions of basketball players, taking into account their types of temperament.

3. To define the effectiveness and activity of players during the game, taking into account their types of temperament.

\section{RESEARCH METHODS}

In order to achieve the aim we used the complex of methods, which provide the set objectives solution. Experimental work was held in national teams of higher educational establishments in Izhevsk (Russia) during season 2017-2018. We analyzed and summarized literature, defined the types of temperament among basketball players 
using hardware controlled «D\&K-TEST» test (season 2017-2018).

Basketball players from national teams of higher educational establishments took part in preliminary research works (27 people). In order to define the amount of the fulfilled by the players technical-tactical actions during the game we used video shooting from three points. Video analysis was realized individually for each player, shooting was held using CANON MV70o camera, results were handled using computer program Media Player Classic.

In order to define the effectiveness of each kind of technical-tactical action we used the following formula of effectiveness coefficient (EC) calculation:

$$
E C=N T T A C \times 100 \% \quad N T T A g
$$

where NTTAc- number of technical-tactical actions fulfilled correctly; NTTAg - general number Table 1 -Number and effectiveness of technical-tactical actions fulfillment(correct)during the game by basketball players with different types of temperament(season 2017-2018)

\begin{tabular}{|c|c|c|c|c|c|c|c|c|c|c|}
\hline \multirow{2}{*}{ TTA } & \multicolumn{2}{|c|}{$1^{\text {st }}$ type } & \multicolumn{2}{|c|}{$2^{\text {nd }}$ type } & \multicolumn{2}{c|}{$3^{\text {rd }}$ type } & \multicolumn{2}{|c|}{$4^{\text {th }}$ type } & \multicolumn{2}{c|}{$5^{\text {th }}$ type } \\
\cline { 2 - 12 } & amount & $\%$ & amount & $\%$ & amount & $\%$ & amount & $\%$ & amount & $\%$ \\
\hline $\begin{array}{c}\text { Attacking } \\
\text { passes }\end{array}$ & 18 & 78,3 & 21 & 84,0 & 23 & 92,0 & 19 & 90,4 & 12 & 85,7 \\
\hline $\begin{array}{c}\text { Points for the } \\
\text { game }\end{array}$ & 2,3 & 76,6 & 10,9 & 81,2 & 6 & 86,7 & 7 & 83,4 & 2 & 50.5 \\
\hline Throws & 5,6 & 54,3 & 8,3 & 67,8 & 12 & 72,8 & 11 & 75,6 & 3 & 48,9 \\
\hline Ball tackle & 3,9 & 65,0 & 6,7 & 70,3 & 9 & 69,3 & 8 & 72,1 & 5 & 52,1 \\
\hline Ball lay-up & 2,6 & 45,7 & 7,3 & 68,9 & 11,5 & 65,7 & 5,9 & 68,9 & 3,6 & 54,7 \\
\hline $\begin{array}{c}\text { Ball picking(o/ } \\
\text { op) }\end{array}$ & 7,1 & 34,7 & 8.9 & 80,3 & 5,8 & 79.7 & 6,9 & 71,7 & 4,6 & 65,3 \\
\hline \begin{tabular}{c} 
Penalty throws \\
\hline
\end{tabular} & 2,1 & 45,8 & 3,6 & 65,7 & 4,5 & 80,3 & 3,2 & 75,9 & 3.8 & 70,3 \\
\hline
\end{tabular}

Note: TTA - technical-tactical actions; the $1^{\text {st }}$ type -phlegmatic-choleric (introvert); the $2^{\text {nd }}$ type- sanguine-choleric (introvert); the $3^{\text {rd }}$ type-sanguine-choleric (extra-introvert); the $4^{\text {th }}$ type-sanguine-melancholic; the $5^{\text {th }}$ type - melancholic; o/op - ball picking under own backboard and the backboard of the opponent

Table $\mathrm{q}$ shows that playing activity of basketball players during the competitions includes technical-tactical actions fulfillment, taking part in playing situations. In our example the volume of TTA, fulfilled by the players of the team, and the effectiveness of their playing activity are analyzed, taking into account the types of players' temperament. It was mentioned that TTA of technical-tactical actions, fulfilled by the players. The indices of playing activity analysis of each player were registered in a separate card, were defined according to the types of temperament and were handled with the help ofmathematical statistics methods.

\section{RESULTS AND DISCUSSION}

Basketball as a team game includes total volume of technical-tactical movements, which are fulfilled by the players of the team in connections, penalty throws, simple throws and many other attacking and defensive actions, fulfilled by the players within the definite time period playing actions.

The results of the average amount of effective technical-tactical actions analysis, fulfilled during the game by basketball players with different types of temperament, are presented in table 1. 
conditioned by psycho-emotional state and psychic readiness state. TTA effectiveness is higher among the representatives of the $2^{\text {nd }}, 3^{\text {rd }}$ and the 4 th types of temperament. However,there is psycho-emotional break-down among basketball players of the $2^{\text {nd }}$ and the $3^{\text {rd }}$ types. This demands timely correction of Table 2 - The indices of effectiveness of the playing activity, taking into account basketball players' types of temperament

\begin{tabular}{|c|c|c|c|c|c|c|c|c|c|c|}
\hline \multirow{2}{*}{ TTA } & \multicolumn{2}{|c|}{$1^{\text {st }}$ type } & \multicolumn{2}{|c|}{$2^{\text {nd }}$ type } & \multicolumn{2}{|c|}{$3^{\text {rd }}$ type } & \multicolumn{2}{|c|}{$4^{\text {th }}$ type } & \multicolumn{2}{|c|}{$5^{\text {th }}$ type } \\
\hline & amount & $\%$ & amount & $\%$ & amount & $\%$ & amount & $\%$ & amount & $\%$ \\
\hline TTAcorrect & 41,6 & & 66,7 & & 71,8 & & 61 & & 34 & \\
\hline TTAgeneral & 51,3 & 80,3 & 73 & 91,4 & 80,3 & 89,4 & 73 & 83,6 & 80 & $4<, 2$ \\
\hline
\end{tabular}

For example, general amount of correctly fulfilled TTA in players with phlegmatic-choleric (introvert) type of temperament was 41,6 times in terms of general amount of TTA 51,3. At the same time, game effectiveness index was 80,3\% (tables 1and 2). Among - sanguine-choleric (introvert) type general amount of correctly fulfilled TTA was 66,7 times in terms of general amount of TTA 73. The game effectiveness index was 91,4\% (tables 1,2). The players of this type of temperament were more active during the game and had higher effectiveness of movements, than the representatives of phlegmaticcholeric (introvert) type of temperament.

The same situation is among the representatives of sanguine-choleric (extraintrovert) type of temperament, where general amount of correctly fulfilled TTA was 71,8 times in terms of general amount of TTA 80,3, the game effectiveness index was $-89,4 \%$ (tables 1, 2).

Among the representatives of sanguinemelancholic type of temperament general amount of correctly fulfilled TTA was 61 times in terms of general amount of TTA 73, the indices of game effectiveness were83,6\% (tables 1,2).

Among the representatives of melancholic type of temperament competitive activity the amount of correctly fulfilled TTA was 34 times, general amount of TTA was 80 times, at the same time, there were low values of effectiveness indices $-42,2 \%$ (table 2).

Taking into account the results of presented indices of players with different types of temperament we can transform playing competitive psycho-emotional state among players.

Table 2 presents the indices of basketball players' playing activity effectiveness coefficient, taking into account their types of temperament.

activity towards the state of psychic readiness of players for the game. It is mentioned that the dynamics of the used TTA ratio in the game depends on many components of players' psychological state.

During pre-competitive training period the use of great amount of TTA prevails, but at the same time, the unit weight of correct TTA is considerably lower. During the competitive period we revealed correct and not successful TTA increase among the players, connected with their psychic state.

In order to define the effectiveness of competitive activity it is necessary to define playing activity of basketball player, taking into account their types of temperament. For this purpose we used the method of playing activity expert evaluation. Not only correct actions of a player were evaluated, but also taking into account simple and complicated playing situations. It is necessary to estimate basketball players' competitive activity according to point system. In this case not only the quality (correctness and incorrectness) of TTA fulfillment is estimated, but also their effectiveness, the level of difficulty and success of the created playing situation on the playing ground. It is necessary to divide TTA into complicated and simple in order to analyze competitive activity of basketball players. Points help to stimulate psychologically each player. Similar research works, held by the authors, proved their effectiveness in different kinds of activity [15].

E.V. Fedotova (2007) in her work, dedicated to all sides of competitive activity study in field hockey, proved effectiveness estimation of competitive activity using different systems of evaluation [16]. 
In our example for evaluation we used 5-point system, where playing situation and each index were estimated in points. If TTA and playing situations are realized precisely, effectively and correctly, creating scoring chances, then the mark is with plus, and if TTA and playing situations are fulfilled not precisely and don't lead to scoring chances, then the mark is with minus.

Table 3 presents the indices of successful and non-successful TTA and playing situations of basketball players expert evaluation.

5 experts were given the records of evaluation Table 3 - Expert evaluation indices of successful and non-successful TTA and playing situations in basketball players

\begin{tabular}{|c|c|c|c|c|c|}
\hline \multirow{2}{*}{ TTA } & $1^{\text {st }}$ type & $2^{\text {nd }}$ type & $3^{\text {rd }}$ type & $4^{\text {th }}$ type & $5^{\text {th }}$ type \\
\hline & mark & mark & mark & mark & mark \\
\hline Successful attacking passes & $+3,5$ & $+4,5$ & $+5,0$ & $+4,7$ & $+3,2$ \\
\hline \multicolumn{6}{|l|}{ Non-successful attacking passes } \\
\hline Successful throws & $+3,5$ & $+4,7$ & $+5,0$ & $+4,3$ & $+3,1$ \\
\hline \multicolumn{6}{|l|}{ Non-successful throws } \\
\hline Balltackling & $+3,2$ & $+4,2$ & $+3,8$ & $+4,3$ & +2.7 \\
\hline \multicolumn{6}{|l|}{ Non-successful attempt of ball tackling } \\
\hline Ball lay-up & $+3,0$ & $+4,5$ & +4.5 & $+4,3$ & \\
\hline \multicolumn{6}{|l|}{ Balllay-up,leading tofoul } \\
\hline Ball picking (o/op) & + & + & + & + & + \\
\hline \multicolumn{6}{|l|}{ Non-successfulattempts of ball picking } \\
\hline Penalty throws & + & + & + & + & + \\
\hline \multicolumn{6}{|l|}{$\begin{array}{l}\text { Non-successful throws } \\
\text { Scoring attack prevention by the player }\end{array}$} \\
\hline $\begin{array}{c}\text { Effective scoring technique of TTA and } \\
\text { playing situations }\end{array}$ & + & + & + & + & + \\
\hline Effective defense and attack & + & + & + & + & + \\
\hline
\end{tabular}

Thus, studied by us second, third, fourth types of temperament are the most active, emotional, accurate in playing situations solution. Theyarethemostsuitabletypesforteamgame. For them it is necessary to plan psycho-regulating means of psychological training, as because of high level of emotionality and activity they quicker lose interest in effective game. They need more stimulation using severe psychological-pedagogical methods of upbringing. They should use means, which decrease emotional level of excitement in order to prevent their over-tension. They are susceptible to external factors, their reaction is emotional, quick and energetic, without own psychic and functional state control. with the main technical-tactical actions of players, where they put marks to each player of the team, without knowing the type of their temperament.

According to the results of the held expert evaluation, presented in table 3 , we underline that the players of the $2^{\text {nd }}, 3^{\text {rd }}$ and the $4^{\text {th }}$ types of temperament gained more positive marks, than negative ones. The players with the $1^{\text {st }}$ and the $5^{\text {th }}$ types of temperament showed insufficient activity during the game and gained in the average 3,76 points.
In the second record experts estimated psychic features level according to the following indices: activity, passiveness, emotionality, energy, plasticity, excitement, tempo of reactions, behavior in difficult playing situation and the quality of playing situational objectives fulfillment.

It was mentioned that the representatives of different types of temperament have different demonstrations of psychic state during the game. The received results of players' psychic state expert evaluation, taking into account their temperament, we would analyze in our further works.

In our opinion, expert evaluation helps to estimate more objectively the actions of each player. Positive marks players got for the quality of TTA 
fulfillment and an effective participation in playing successful and non-successful situations. Negative marks they got for the mistakes and for noneffective playing situations creation. Such variant of competitive activity estimation, taking into account players' type of temperament, helps to improve the effectiveness of collective TTA and the contribution of each player into team work.

\section{CONCLUSION}

Making the analysis and giving expert evaluation of basketball players' competitive activity at a higher educational establishment, we came to the following conclusion:

- the ability of players to realize effective TTA depends on their personal psychic qualities;

- successful and non-successful TTA and the participation in playing situations analysis helps to correct timely the state of players' psychic readiness;

- taking into account the temperament of players helps to realize effectively psycho regulating means of psychic training;

-the effectiveness and activity of the game estimation, taking into account the types of temperament, leads to structural changes in playing motor activity of the teams and the separate players;

- the volume of activity in playing situations increases among the players owing to the importance of typological personality features increase in training.

\section{REFERENCES}

1. Alatortsev V.A. Gotounost' sportsmen $k$ sorevnovaniyam: opyt psihologicheskogo issledovaniya [An athlete's readiness for competitions: the experience of psychological research]. Moscow: Physical culture and sport. 2009: 31 (In Russ., In Engl.).

2. Babushkin G.D., Smolentseva V.N. Autovozdejstvie I geterovozdejstvie pri razvitii samoobladaniya u sportsmenov [Autoinfluence and hetero-influence during self-control development among athletes]. Saratov: Saratov State Pedagogical Institute. 1996: 149-151 (In Russ., In Engl.).

3. Gordon S.M., Ilin A.B. Psychological readiness estimation. Teroiya I practica fizicheskoj kul'tury = Theory and practice of physical culture . 2004; 2: 45-49 (In Russ., In Engl.).

4. Gibadullin I.G., Pushakarev A.V., Pushkareva A.M. Dynamics of special physical readiness among young basketball players from the training groups in basketball. Kazanskaya nauka. 2016; 2: 108-110 (In Russ.).

5. Grigoryants I.A. Problem of readiness and pre-competitive training organization in gymnastics. Teroiya I practica fizicheskoj kul'tury = Theory and practice of physical culture. 2001; 8: 22-28 (In Russ., In Engl.).

Zakirov D.R. Studying the state of psychic readiness among Greco-Roman style wrestlers in different periods of training at the stage of sports improvement. Pedagogiko-psychologicheskie I mediko-biologicheskie problemy fizicheskoj kul'tury I sporta. 2012; 4(25): 41-50. URL: http:// www.journalsport.ru/images/vipuski/7-1/4.pdf (In Russ.)

6. Ilin E.P. Psihologiya voli [Psychology of will power]. Saint-Petersburg: Piter. 2009: 368 (In Russ., In Engl.).

7. Karlenko V.P., Karlenko N.V. Ispol'zovanie komp'yuternoj tehnologii $B D \& K-$ Test $v$ praktike podgotovki kvalificirovannyh sportsmenov [D\&K-TEST computer technology use in practice of qualified athletes training]. AllRussian scientific-research Institute of physical culture and sport. Moscow 2003: 134 - 136 (In Russ., In Engl.).

8. Kamalieva G.A. Modular technology of training athletes for competitive obstacles and difficulties overcoming. Obrazovanie I samorazvitie [Education and self-development]. 2010; 4: 36-42 (In Russ.).

9. KuznetsovaZ., KuznetsovA., MutaevaI., KhalikovG., ZakharovaA. Athletes preparation based on a complex assessment of functional state. In Proceedings of the $3^{\text {rd }}$ International Congress on Sport Sciences Research and Technology support. SCITEPRESS. 2015: 156-160.

10. Petrov R.E., Mutaeva I.Sh., Ionov A.A. Aerobicthresholdand potentialities of cardiovascular system determination and estimation among cross country racers (boys) on the basis of gradually- 
increasing bicycle-ergometric load. Pedagogikopsyhologicheskie i mediko-biologicheskie problemy fizicheskoj kul'tury I sporta = The Russian Journal of Physical Education and Sport. 2018; 13(2): 198206. DOI 10.14526/02_2018_326 (In Russ., In Engl.)

11. Puni A.Ts. Athlete's will-power upbringing. Saint-Petersburg: KOIZ. 2008: 112.

12. Radchenko Yu. Interconnection between psycho-physiological functions and the time of techniques fulfillment among highlyqualified wrestlers. Pedagogika, psihologiya I medico-biologicheskie problemy fizicheskogo vospitaniya I sporta [Pedagogics, psychology and medical-biological problems of physical upbringing and sport]. 2009; 1: 114-118 (In Russ.).

13. Rudik P.A. Psihologiya sporta [Psychology of sport]. Moscow 2009: 408 (In Russ.).

14. Sadiev N.N. The system of control means and educational success estimation among cadets of military higher educational establishments in physical culture. Materialy Vseroosijskoj nauchno-prakticheskoj konferencii $s$ mezhdunarodnym uchastiem [Materials of All-Russian scientific-practical conference with international participation]. Saint-Petersburg "Strategic directions of physical culture higher education reformation". 2014; 3: 292-298 (In Russ.).

15. Fedotova E.V. Sorevnovatel'naya deyatel'nost' I podgotovka sportsmenov vysokoj kvalifikacii hokeya na trave [Competitive activity and training athletes of high qualification in field hockey]. Kazan: "LogosCenter". 2007: 368-369 (In Russ.).

16. Amorose A.J., Anderson-Butcher D. Autonomy-supportive coaching and selfdetermined motivation in high school and college athletes: A test of self-determination theory. 2007; 8: 854-873.

17. Chantal Y., Bernache-Assollant I. A prospective analysis of self-determined sport motivation and sportpersonship orientations. Athletic Insight: The Online Journal of Sport Psychology. 2003; 5(4).

18. Chantal Y., Robin P., Vernat J.P., Bernache-Assollant I. Motivation, sportpersonship and athletic aggression: A mediational analysis. Psychology of Sport and Exercise. 2005; 6: 233249.

19. Hollembeak J., Amorose A.J. Perceived coaching behaviors and college athletes' intrinsic motivation: A test of self-determination theory. Journal of Applied Sport Psychology. 2005; 17: 20-36.

20. Lane A.M., Chappell R.H. Mood and performance relationship at the world student games basketball competition. Journal of Sport Behavior. 2001; 24: 182-196.

21. Aries Jose L., Argudo Francisco M., Alonso Jose I. Effect of the ball mass on the one-onone game situation in 9-11-year old boys' basketball. European Journal of Sport Science. 2012; 12(3): 225-230.

\section{Submitted: 01.11.2019}

\section{Author's information:}

Pushkarev A.V. - Senor Lecturer, Udmurtiya State University, 426061, Russia, Izhevsk, Voroshilov str., House 72, Block 4, e-mail: Alexeipushkarev@mail.ru 